\title{
Computer Modelling of Phase Transformation from Work-hardened Austenite
}

\author{
Minoru UMEMOTO, Akifumi HIRAMATSU, () Akio MORIYA, ${ }^{2)}$ Tsutomu WATANABe, ${ }^{2)}$ Shigenobu \\ NANBA, ${ }^{3)}$ Norihiro NAKAJIMA, ${ }^{4}$ Goro ANAN ${ }^{4)}$ and Yuichi HIGO ${ }^{1)}$
}

Department of Production Systems Engineering, Toyohashi University of Technology, Hibarigaoka, Tempaku-cho, Toyohashi, Aichi-ken, 441 Japan $\quad$ 1) Steel R \& D Laboratories, Nisshin Steel Co, Ltd, Showa-cho, Kure, Hiroshima-ken, 737 Japan. $\quad 2$ 2) Kure Works, Nisshin Steel Co., Ltd., Showa-cho, Kure, Hiroshima-ken, 737 Japan. Research Laboratories, Kobe Steel, Ltd., Wakinohama-cho, Chuo-ku, Kobe, Hyogo-ken, 651 Japan. Works, Kobe Steel, Ltd., Kanazawa-cho, Kakogawa, Hyogo-ken, 675-01 Japan

3) Iron \& Steel 4) Kakogawa

(Received on September 27, 1991; accepted in final form on January 24, 1992)

\begin{abstract}
To make quantitative prediction of microstructure in HSLA steels produced by isothermal or continuous cooling transformation, transformation kinetics of various phases were modeled thermodynamically. Five kinds of phases, i.e. polygonal ferrite, Widmanstätten ferrite, pearlite, bainite and martensite, and 10 alloying elements were taken into account. A program was developed on the basis of this model. Out line of the involved transformation kinetics are presented in this paper. The effects of work-hardening of austenite on the nucleation and growth rates of various phases are discussed and a mathematical model of transformation kinetics from work-hardened austenite is also presented.
\end{abstract}

KEY WORDS: thermodynamics; phase transformation; kinetics; microstructure; ferrite; pearlite; bainite; martensite; HSLA steel.

\section{Introduction}

In the last two decades thermomechanical processing has been developed to improve strength, toughness, ductility and weldability of hot rolled products. This process consists of controlled rolling and accelerated cooling. The controlled rolling consists of three stages ${ }^{1}$; (1) deformation in the high-temperature austenite region to attain grain refinement via repeated deformation and recrystallization; (2) deformation in the non-recrystallized austenite region to increase nucleation sites for ferrite grains via deformed austenite; (3) deformation in the austenite-ferrite two-phase region to increase ferrite strength. Accelerated cooling during austenite-to-ferrite transformation produces fine ferrite structure mixed with bainite or martensite islands. High strength steel with good toughness at low temperature and superior weldability can be produced by the optimum combination of controlled rolling and accelerated cooling. From the end of the 60 's, enormous studies of controlled rolling and its actual practice in the plate mill have been carried out. Studies of accelerated cooling after hot rolling started in the early 60's in BISRA ${ }^{2,3)}$ in England. Accelerated cooling in the hot strip mill was also studied and a series of high-strength low-alloy (HSLA) steels were developed. ${ }^{4,5)}$ The combination of accelerated cooling with controlled rolling has been recognized to further improve mechanical properties by both ferrite grain refinement and transformation strengthening. The actual practice of accelerated cooling in the plate mill started in the late $70^{\prime} \mathrm{s}^{6)}$ and accelerated cooling after controlled rolling has become a major thermomechanical process for producing HSLA steel plate.

In recent years, metal forming industry has been striving for quality improvement and cost reduction to meet the increasingly stringent specification requirements and strong competition in the world market. There is an increasing need to link the properties of steel products to the processes that are employed in their manufacture. It has been recognized that effective control of mechanical properties and quality can only be achieved by an improved understanding of the microstructural evolution in the each step of rolling and cooling processes. Since the mechanical properties of steels depend on their microstructure such as grain size, second phase, dislocation density, precipitates, and alloying elements, an accurate prediction of the microstructure is essential to a reliable estimation of mechanical properties. Considerable research has been carried out in the past two decades on the computer modelling of thermomechanical process. The so called 'complete model' is usually consisted with hot deformation, transformation and mechanical properties prediction models. The hot deformation model predicts austenitic microstructural evolution in hot rolling and transformation model predicts transformation from austenite during cooling. When the steel contains microalloying elements, precipitation model was also constructed. Mathematical 
modelling of thermomechanical process started from the construction of hot rolling model. During the mid to late 70's Sellars and co-workers ${ }^{7-9)}$ demonstrated that by developing mathematical models for the individual metallurgical events that occur during rolling, and then combining these in the correct metallurgical sequence with process models for a given rolling mill, it was possible to follow the evolving microstructure as a function of macroscopic process change.

The first mathematical modelling of phase transformation during cooling on the basis of physical metallurgy was done by Kirkaldy ${ }^{10)}$ in the mid 70 's. His approach to model continuous cooling transformation has been extended to various transformation products and complex cooling conditions by several researchers. ${ }^{11-13)}$ The mathematical modelling of phase transformation which occurs in the actual thermomechanical process was done first by Saito et al. ${ }^{14)}$ for non work-hardened austenite and Esaka et al. ${ }^{15)}$ for work-hardened austenite. Although these models were developed on an empirical or semi-empirical basis, these works triggered off the further refined phase transformation models. It is only recent that theories of nucleation and growth and thermodynamics have been adopted for the modelling of phase transformation. ${ }^{16-27)}$

The present authors developed a computer model for predicting the phase transformation during cooling from work-hardened austenite. In this paper the metallurgical principle of this model will be presented. The concepts which are already presented in somewhere else $^{26)}$ will be mentioned briefly. The estimation of ferrite/austenite interfacial area, conditions for pearlite transformation to start at ferrite/austenite interface and isothermal and continuous cooling transformation kinetics of Widmanstätten ferrite and bainite which will be introduced for the first time will be explained in detail. The application of the developed computer program was presented by Inoue et al. ${ }^{28)}$ and will not be mentioned in this paper.

\section{Thermodynamics}

Thermodynamic data such as driving force for nucleation, free energy change associated with phase transformation, equilibrium compositions etc. are essential requirements for the theoretical simulation of transformation kinetics. In the present study the regular solution sublattice model proposed by Hillert and Staffanson ${ }^{29)}$ is adopted from its simplicity and popularity. The present thermodynamic program can treat 10 elements $(\mathrm{Fe}-\mathrm{C}-\mathrm{Si}-\mathrm{Mn}-\mathrm{Ni}-\mathrm{Cr}-\mathrm{Mo}-\mathrm{V}-\mathrm{W}-\mathrm{Cu})$ system under para-equilibrium condition. The free energy of work-hardened austenite is calculated by adding the strain energy of dislocations to that of non-deformed austenite. The strain energy associated with dislocations is expressed by

$$
E=V^{m} \rho \frac{\mu b^{2}}{4 \pi K} \ln \left(\frac{R_{d}}{b}\right)
$$

where $V^{m}$ is the molar volume, $\rho$ is the dislocation density, $\mu$ is the shear modulus, $b$ is the size of Burgers vector, $R_{d}$ is the inter dislocation distance $\left(=0.5 \rho^{-1 / 2}\right)$,
$K$ is the constant. If dislocation density is given, all the transformation behavior can be calculated for workhardened austenite. The detail of the developed program will be presented elsewhere. ${ }^{30}$

\section{Isothermal Transformation Kinetics}

\subsection{Polygonal Ferrite}

Let $V_{F}(t)$ be the volume of ferrite at time $t$ and ${ }^{E} V_{F}$ be the volume of ferrite at equilibrium condition. The isothermally transformed volume fraction of ferrite $F_{F}(t)$ at time $t$ is defined as

$$
F_{F}(t) \equiv \frac{V_{F}(t)}{{ }^{E} V_{F}}=\frac{V_{F}(t)}{V_{0}} \frac{C_{\gamma}-C_{\alpha}}{C_{\gamma}-C_{0}}
$$

where $V_{0}$ is the volume of a specimen, $C_{0}$ is the initial carbon content and $C_{\gamma}$ and $C_{\alpha}$ are the equilibrium carbon content in austenite $(\gamma)$ and ferrite $(\alpha)$, respectively. The transformed ferrite fraction with respect to a whole specimen is

$$
X_{F}(t)=\frac{V_{F}(t)}{V_{0}}=\frac{C_{\gamma}-C_{0}}{C_{\gamma}-C_{\alpha}} F_{F}(t)
$$

According to the classical nucleation theory, nucleation rate is expressed as

$$
I_{F}=K_{1} \frac{D_{c}\left(1-\bar{C}_{y}\right)}{\sqrt{T}} \exp \left(-\frac{K_{2}}{\Delta G_{F}^{2} T}\right) .
$$

where $D_{c}$ is the volume diffusion coefficient of carbon in austenite, $\bar{C}_{y}$ is the average carbon content in untransformed $\gamma ; \Delta G_{F}$ is the driving force for $\alpha$ nucleation and $K_{1}$ and $K_{2}$ are the fitting parameters. As the volume fraction of $\alpha$ increases, carbon content in untransformed austenite increases. Thus, $\bar{C}_{\gamma}$ in Eq. (4) is a variable. However, since ferrite nucleation occurs mostly in the early stage of transformation, it can be assumed that nucleation rate is constant.

The growth rate of ferrite was derived by Zener, ${ }^{31)}$ and the radius of ferrite at time $t$ is given by

$$
R=a t^{1 / 2}
$$

where $a$ is a parabolic rate constant and is given as

$$
a=\frac{K_{3} D_{c}^{1 / 2}\left(C_{\gamma}-C_{0}\right)}{\left(C_{\gamma}-C_{\alpha}\right)^{1 / 2}\left(C_{0}-C_{\alpha}\right)^{1 / 2}}
$$

where $K_{3}$ is a constant between 1.14 and 1.41. Strictly speaking, Eq. (6) does not hold near the end of transformation where the diffusion fields of carbon in $\gamma$ overlap each other. However, since the carbon content in $\gamma$ at $\alpha / \gamma$ interface is usually very high compared to the initial carbon content especially at low temperature, the parabolic rate constant given by Eq. (6) can be used until near the end of transformation.

When polygonal $\alpha$ forms from polygonal (or recrystallized) $\gamma$, it often nucleates on $\gamma$ grain boundary surface. There are three types of sites on grain boundary, i.e. grain boundary surface, edge and corner. The transformation kinetics of grain boundary nucleation were developed by Cahn. ${ }^{32)}$ Using Cahn's method, ferrite transformation kinetics of grain boundary surface 


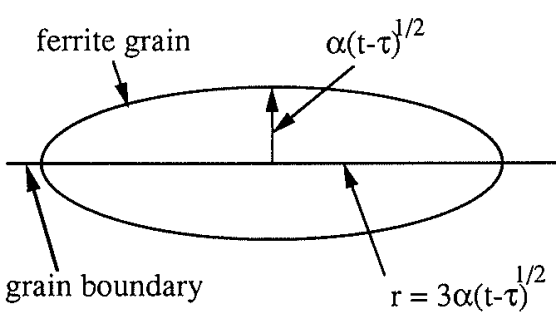

Fig. 1. Schematic illustration showing the shape of growing polygonal ferrite nucleated on austenite grain boundary.

nucleation was derived ${ }^{26)}$ and the isothermally transformed volume fraction of ferrite can be expressed as

$$
\begin{aligned}
& F_{F}(t)=1-\exp \left[-2 S_{\gamma}\left(\frac{C_{\gamma}-C_{\alpha}}{C_{\gamma}-C_{0}}\right) a t^{1 / 2}\right. \\
&\left.\cdot \int_{0}^{1}\left[1-\exp \left\{-\left(\frac{9}{2}\right) \pi I_{F}^{S} a^{2} t^{2}\left(1-2 x^{2}+x^{4}\right)\right\}\right] d x\right]
\end{aligned}
$$

where $S_{\gamma}$ is the $\gamma$ grain boundary area per unit volume and $I_{F}^{S}$ is the nucleation rate of $\alpha$ per unit area of $\gamma$ grain boundary. In the derivation of Eq. (7) the followings were assumed: (1) ferrite nucleates only on $\gamma$ grain boundary surface, (2) the nucleation rate of $\alpha$ per unit area of $\gamma$ grain boundary $I_{F}^{S}$ is independent of time, (3) $\alpha$ grains grow as ellipsoid with the aspect ratio of $3: 1^{33}$ ) as shown in Fig. 1, (4) the short radius of $\alpha$ grain is $r=a \cdot t^{1 / 2}$, and $a$ is constant with time.

\subsection{Pearlite}

About the nucleation of pearlite, $\gamma$ grain boundary is the preferential nucleation site in eutectoid steels. However, in low carbon steels pearlite transformation starts after most of the $\gamma$ grain boundaries are occupied by ferrite and pearlite mostly nucleates at $\alpha / \gamma$ interface. Thus in low carbon steel the following two conditions are considered to be required for the nucleation and growth of pearlite. One is that the $\alpha / \gamma$ interface moves slowly enough so that the pearlite (actually cementite) can nucleate on the moving $\alpha / \gamma$ interface. Second is that the average carbon content in untransformed $\gamma$ should exceeds the equilibrium carbon content of $\gamma$ with respect to cementite.

The first condition is equivalent to say that the incubation time for cementite $(\theta)$ nucleation must be shorter than the time required for the $\alpha / \gamma$ interface to move the length of critical radius of cementite nuclei, that is

$$
\frac{d R}{d t}<\frac{h_{c}}{\tau_{\theta}}
$$

where $h_{c}$ is the critical height of cementite nuclei and $\tau_{\theta}$ is the incubation time for nucleation of cementite. If the cementite nuclei on $\alpha / \gamma$ interface is the segment of a sphere as shown in Fig. 2,

$$
h_{c}=\frac{2 \varepsilon}{\Delta G_{\theta}}
$$

where $\varepsilon=\sigma_{\gamma \theta}+\sigma_{\alpha \theta}-\sigma_{\alpha \gamma}$ and $\sigma_{\gamma \theta}, \sigma_{\alpha \theta}$ and $\sigma_{\alpha \gamma}$ are the $\gamma / \theta$,

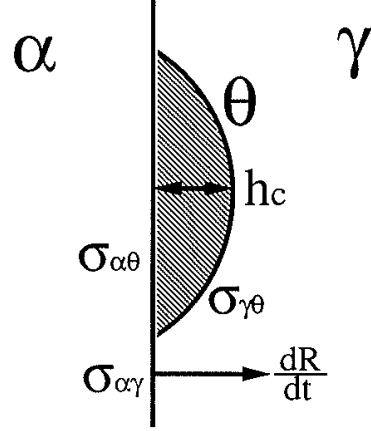

Fig. 2. Schemetic illustration of cementite nucleus nucleated on moving $\alpha / \gamma$ interface. $h_{\mathrm{c}}$ is the critical hight of cementite $(\theta)$ and $d R / d t$ is the moving rate of $\alpha / \gamma$ interface. $\sigma_{\gamma \theta}, \sigma_{\alpha 0}$ and $\sigma_{\alpha \gamma}$ are the $\gamma / \theta, \alpha / \theta$ and $\alpha / \gamma$ interfacial energies, respectively.

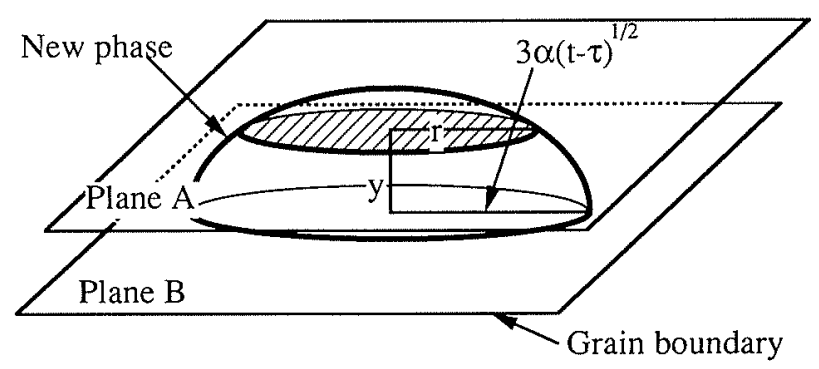

Fig. 3. Schematic diagram showing a ferrite grain nucleated on grain boundary $B$ and a plane $A$ parallel to $B$ with distance $y$ apart.

$\alpha / \theta$ and $\alpha / \gamma$ interfacial energies, respectively. $\tau_{\theta}$ can be calculated by the equation proposed by Russell. ${ }^{34)}$

$$
\tau_{\theta}=\frac{K_{4} T}{\Delta G_{\theta}^{2} \cdot D_{c}}
$$

where $K_{4}$ and $\Delta G_{\theta}$ are a constant and the driving force for nucleation of cementite, respectively. Thus, we obtain

$$
\frac{h_{c}}{\tau_{\theta}}=K_{5} \frac{\Delta G_{\theta} \cdot D_{c} \cdot \varepsilon}{T}
$$

where $K_{5}$ is a constant.

The $\alpha / \gamma$ interface area per unit volume of specimen, $S_{\alpha / \gamma}$, can be simply estimated assuming that ferrite nucleates at $\gamma$ grain surface under the condition of site saturation and grow within $\gamma$ grains. Such assumption gives

$$
S_{\alpha / \gamma}=S_{\gamma}\left(1-X_{F}\right)^{2 / 3}
$$

More accurate calculation of $\alpha / \gamma$ interfacial area can be done as follows. Consider a plane boundary $B$ of infinite extent and an arbitrary plane $A$ parallel to $B$ at a distance $y$ from $B$ as shown in Fig. 3. A ferrite grain starting to grow at plane $B$ at time $\tau$ have a circular intersection with plane $A$ and the radius at time $t$ is

$$
\begin{aligned}
& r=3\left\{a^{2}(t-\tau)-y^{2}\right\}^{1 / 2} \text { when } a(t-\tau)^{1 / 2}>y \\
& r=0 \quad a(t-\tau)^{1 / 2}<y
\end{aligned}
$$

If we assume that ferrite grain can grow without impingement and nucleate everywhere in the $\gamma$ grain boundary surface, the extended circumference of all ferrite grains on plane $A$ at time $t$ nucleated from time 
0 to $t$

$$
\begin{aligned}
L_{\alpha / \gamma}^{t} & =2 \pi I_{F}^{S} \int_{0}^{t-\left(y^{2} / a^{2}\right)}\left\{9 a^{2}(t-\tau)-9 y^{2}\right\}^{1 / 2} d \tau \\
& =4 \pi I_{F}^{S} a t^{3 / 2}\left(1-x^{2}\right)^{3 / 2}
\end{aligned}
$$

where $x=1 /\left(a t^{1 / 2}\right)$. The total length of $\alpha / \gamma$ line boundary on plane $A, L_{\alpha / \gamma}$, is given by the product of $L_{\alpha / \gamma}^{t}$ and untransformed area fraction on plane $A$,

$$
L_{\alpha / \gamma}=L_{\alpha / \gamma}^{t}\left(1-Y_{F}\right)
$$

where $Y_{F}$ is the transformed fraction of $\alpha$ on plane $A$ and is given as ${ }^{26)}$

$$
Y_{F}=1-\exp \left\{-\frac{9}{2} \pi I_{F}^{S} a^{2} t^{2}\left(1-2 x^{2}+x^{4}\right)\right\}
$$

The $\alpha / \gamma$ interfacial area due to all the ferrite grains nucleated on unit area of $\gamma$ grain surface is

$$
A_{\alpha / \gamma}^{e}=\int_{0}^{1} L_{\alpha / \gamma} d x
$$

Since $S_{\gamma}$ can be expressed using $\gamma$ grain diameter $D_{\gamma}$ as $4 /\left(\sqrt{\pi} D_{\gamma}\right)$, the $\alpha / \gamma$ interfacial area per unit volume of a specimen is

$$
\begin{aligned}
S_{\alpha / \gamma}^{e}= & \frac{16 \sqrt{\pi}}{D_{\gamma}} I_{F}^{S} a t^{3 / 2} \int_{0}^{1}\left[\left(1-x^{2}\right)^{3 / 2}\right. \\
& \left.\cdot \exp \left\{-\frac{9}{2} \pi I_{F}^{S} a^{2} t^{2}\left(1-2 x^{2}+x^{4}\right) d x\right\}\right]
\end{aligned}
$$

In the above derivation $\gamma$ grain boundary is assumed to be planar. If we take into account the collision of $\alpha$ grains nucleated at $\gamma$ grain boundaries face each other, the actual $\alpha / \gamma$ interfacial area per unit volume of a specimen is

$$
S_{\alpha / \gamma}=S_{\alpha / \gamma}^{e}\left(1-X_{F}\right)^{2 / 3}
$$

Figure 4 shows an example of calculated $S_{\alpha / \gamma}$ as a function of $X_{F}$. In this calculation $I_{F}^{S}$ and $a$ are given as $10^{2} / \mathrm{cm}^{2} / \mathrm{s}$ and $4 \times 10^{-4} \mathrm{~cm} / \mathrm{s}^{1 / 2}$, respectively. It is seen that $S_{\alpha / \gamma}$ has a maximum at around $X_{F}=0.5$. This trend is more realistic than the monotonous decrease of $S_{\alpha / \gamma}$ with $X_{F}$ given by Eq. (12).

The growth rate of pearlite is calculated by the equation derived by Hillert ${ }^{35}$

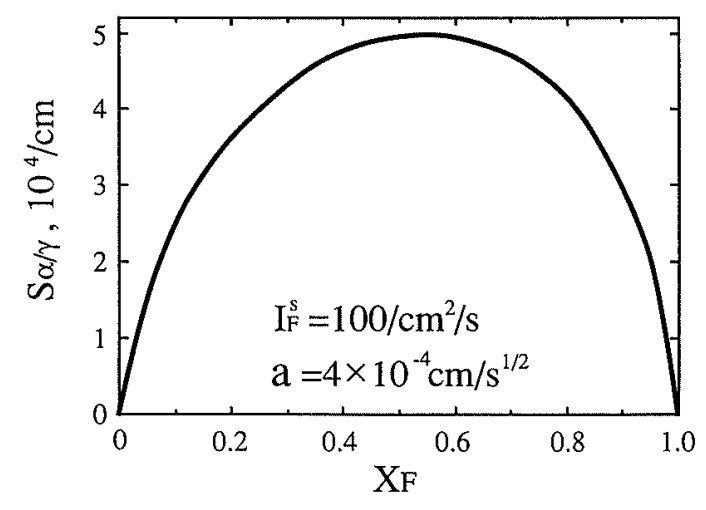

Fig. 4. $\alpha / \gamma$ specific interface area $S_{\alpha / \gamma}$ as a function of transformed fraction of ferrite $X_{F}, I_{F}^{S}$ is the nucleation rate of $\alpha$ per unit area of $\gamma$ grain boundary and $a$ is the parabolic rate constant.

$$
G_{p}=\frac{D_{c}^{\gamma}}{4 \sigma V_{p} R T C_{\gamma}}\left(\Delta G_{p}\right)^{2}
$$

where $V_{p}^{m}$ is the molar volume of pearlite and $\Delta G_{p}$ is the driving force for pearlite transformation.

\subsection{Widmanstätten Ferrite and Bainite}

As proposed by Bhadeshia, ${ }^{36,37)}$ the following conditions were considered to be required for Widmanstätten $\alpha$ and bainite transformation to occur:

$$
\begin{aligned}
& \Delta G_{F}<\Delta F_{N}(=4204-5.96(T-273) \mathrm{J} / \mathrm{mol}) \\
& \Delta G^{\gamma \rightarrow \alpha+\gamma^{\prime}}<F_{1}(=-300 \mathrm{~J} / \mathrm{mol}) \ldots \ldots \ldots \ldots \ldots \ldots \ldots \ldots \ldots \ldots \ldots \ldots \ldots \ldots \ldots \ldots \ldots \ldots \ldots \ldots
\end{aligned}
$$

where $\Delta F_{N}$ is the driving force necessary to obtain a detectable nucleation rate, $\Delta G^{\gamma \rightarrow \alpha+\gamma^{\prime}}$ is the free energy change associated with ferrite formation and $\Delta G^{\gamma \rightarrow \alpha^{\prime}}$ is the free energy change associated with martensitic transformation. $F_{1}$ and $F_{2}$ are the stored energies associated with Widmanstätten $\alpha$ and bainite transformations, respectively. When Eqs. (21) and (22) are satisfied nucleated $\alpha$ grain grows as Widmanstätten $\alpha$, and when Eqs. (21) and (23) are satisfied bainite transformation starts. The value of $\Delta F_{N}$ given in Eq. (21) is the one recalculated using our current thermodynamic program $^{30)}$ and the experimental data of Steven and Haynes. ${ }^{38)}$ The stored energy of Widmanstätten ferrite and bainite, $F_{1}$ and $F_{2}$, are also reevaluated to be -300 and $-600 \mathrm{~J} / \mathrm{mol}$, respectively, from the best fit with the experimental $W_{s}$ and $B_{s}$ data ${ }^{38)}$ in low carbon steels. The values of $\Delta F_{N}, F_{1}$ and $F_{2}$ obtained by the present authors are different from those proposed by Bhadeshia ${ }^{36,37)}$ where $\Delta F_{N}=3.25(T-273)-2180 \mathrm{~J} / \mathrm{mol}, \quad F_{1}=-50 \mathrm{~J} /$ mol, $F_{2}=-400 \mathrm{~J} / \mathrm{mol}$. The nucleus of Widmanstätten $\alpha$ and bainite are considered to be identical with that of polygonal $\alpha$ and nucleation rate is given by Eq. (4).

The growth rate of Widmanstätten $\alpha$ and bainite is described by Trivedi ${ }^{39)}$ as

$$
\begin{gathered}
G_{W F} \text { and } G_{B}=\frac{27 D_{c} \Omega_{*}^{3}}{256 \pi \rho_{c}} \\
\Omega_{*}=\frac{\Omega_{0}}{1-\frac{2}{\pi} \Omega_{0}-\frac{1}{2 \pi} \Omega_{0}^{2}} \ldots \\
\Omega_{0}=\frac{C_{\gamma}-C_{0}}{C_{\gamma}-C_{\alpha}} \ldots \ldots \ldots \\
\rho_{c}=\frac{C_{\gamma}}{\left(C_{\gamma}-C_{\alpha}\right)} \frac{\sigma_{\alpha / \gamma} V_{F}^{m}}{\left(C_{\gamma}-C_{0}\right) R T}
\end{gathered}
$$

where $V_{F}^{m}$ is molar volume of $\alpha$ and $\rho_{c}$ is the curvature at the tip of lath. In the case of Widmanstätten $\alpha, C_{0}$ is a function of time and equal to $\bar{C}_{\gamma}$ while in the case of bainite $C_{0}$ is constant and equal to $\bar{C}_{y}$ at the beginning of bainite transformation.

The isothermal transformation kinetics of bainite for homogeneous and grain boundary surface nucleation can be derived as follows. Assume the shape of bainite as shown in Fig. 5 with curvature $\rho_{c}$ and thickness $h$ similar to that proposed by Trivedi. When bainite nucleates 

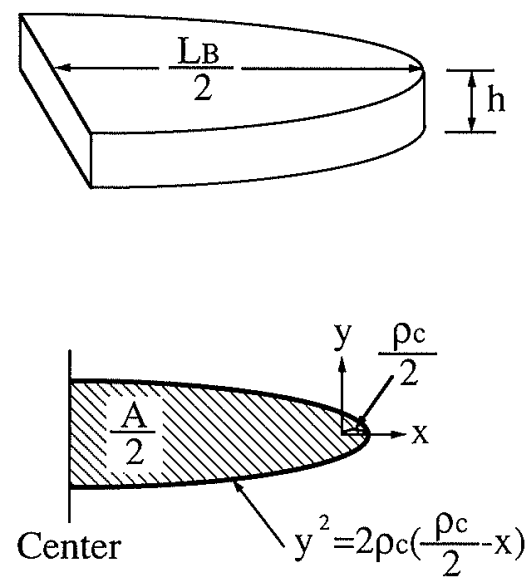

Fig. 5. Schematic illustration of bainite lath nucleated within austenite grain.
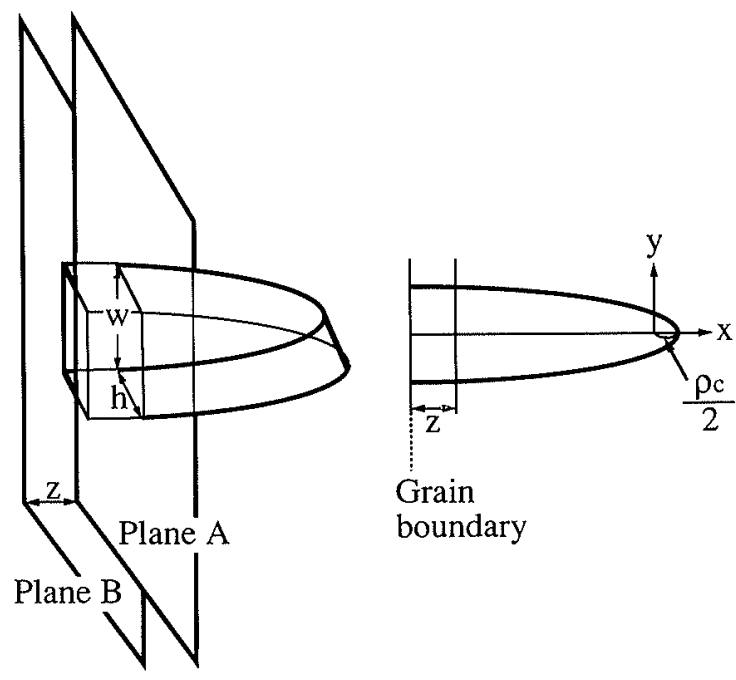

boundary

Fig. 6. Schematic illustration showing the growing bainite lath nucleated on austenite grain boundary.

within $\gamma$ grains the lath length of bainite at time $t$ which nucleated at time $\tau$

$$
L_{B}=2 G_{B}(t-\tau)
$$

The area $A$ in Fig. 5 is given as

$$
A=4 \int_{-\left(L_{B}-\rho_{c} / 2\right)}^{\rho_{c} / 2} \sqrt{2 \rho_{c}\left(\frac{\rho_{c}}{2}-x\right)} d x=\frac{8 \sqrt{2}}{3} \sqrt{\rho_{c}} L_{B}^{3 / 2}
$$

The extended volume due to all the bainite lath nucleated from time 0 to $t$ is

$$
\begin{aligned}
{ }^{e} V_{B}^{h} & =\int_{0}^{t} A h I_{B}^{h} d \tau=\frac{8 \sqrt{2}}{3} \sqrt{\rho_{c}} G_{B}^{3 / 2} h I_{B}^{h} \int_{0}^{t}(t-\tau)^{3 / 2} d \tau \\
& =\frac{16 \sqrt{2}}{15} \rho_{c}^{1 / 2} G_{B}^{3 / 2} h I_{B}^{h} t^{5 / 2} \ldots \ldots \ldots \ldots \ldots \ldots \ldots \ldots \ldots \ldots \ldots \ldots \ldots \ldots \ldots \ldots \ldots \ldots \ldots \ldots \ldots
\end{aligned}
$$

where $I_{B}^{h}$ is the nucleation rate of bainite per unit volume of austenite. Thus bainite fraction transformed is

$$
X_{B}^{h}=1-\exp \left(-\frac{16 \sqrt{2}}{15} \rho_{C}^{1 / 2} G_{B}^{3 / 2} h I_{B}^{h} t^{5 / 2}\right)
$$

The transformation kinetics of grain boundary surface nucleation can be derived as follows. Consider a plane boundary $B$ of infinite extent having a specific nucleation rate $I_{B}^{s}$. Consider an arbitrary plane $A$ parallel to $B$ at a distance $z$ from $B$ as shown in Fig. 6. A bainite lath starting to grow on plane $B$ at time $\tau$ has a rectangle intersection with $A$ whose sides lengths are $w$ and $h$, where $w$ is given by

$$
w=2 \sqrt{2 \rho_{c}} \sqrt{G_{B}(t-\tau)-z}
$$

The extended area fraction on plane $A$ due to ferrite grains nucleated between time $\tau$ and $\tau+d \tau$ is

$$
\begin{array}{rlrl}
d Y_{B}^{e} & =I_{B}^{s} \cdot h \cdot 2 \sqrt{2 \rho_{c}} \sqrt{G_{B}(t-\tau)-z} d \tau \text { when } G_{B}(t-\tau)>y \\
& =0 & \text { when } G_{B}(t-\tau)<y
\end{array}
$$

The extended area fraction on plane $A$ due to all the bainite lath starting between time 0 and $t$ is

$$
\begin{aligned}
& Y_{B}^{e}=\int_{0}^{t-Z / G_{B}} I_{B}^{s} \cdot h \cdot 2 \sqrt{2 \rho_{c}} \sqrt{G_{B}(t-\tau)-z} d \tau \\
& =\frac{4 \sqrt{2}}{3} I_{B}^{s} h \rho_{c}^{1 / 2} G_{B}^{1 / 2}\{t(1-x)\}^{3 / 2}
\end{aligned}
$$

where $x=z /(v t)$. This gives transformed area fraction on plane $A$ as

$$
Y_{B}=1-\exp \left[-\frac{4 \sqrt{2}}{3} I_{B}^{s} h \rho_{c}^{1 / 2} G_{B}^{1 / 2}\{t(1-x)\}^{3 / 2}\right]
$$

The extended volume of the bainite lath nucleated at unit area of grain boundary $B$ is

$$
\begin{aligned}
{ }^{e} V_{B}^{s}= & G_{B} t \int_{0}^{\infty} Y_{B} d z \\
= & G_{B} t \int_{0}^{1}\left[1-\exp \left[-\frac{4 \sqrt{2}}{3} I_{B}^{s} h \rho_{c}^{1 / 2} G_{B}^{1 / 2}\right.\right. \\
& \left.\left.\cdot\{t(1-x)\}^{3 / 2}\right] d x\right]
\end{aligned}
$$

The fraction transformed is given as

$$
\begin{aligned}
& X_{B}^{s}=1-\exp \left[-S_{\gamma} G_{B} t \int_{0}^{1}\left[1-\exp \left[-\frac{4 \sqrt{2}}{3}\right.\right.\right. \\
& \left.\left.\left.\cdot I_{B}^{s} h \rho_{c}^{1 / 2} G_{B}^{1 / 2}\{t(1-x)\}^{3 / 2}\right]\right] d x\right]
\end{aligned}
$$

\subsection{Martensite}

Ms temperature is calculated by the equation proposed by Hsu and Hongbing ${ }^{40)}$

$$
\Delta G^{\gamma \rightarrow \alpha^{\prime}}=-1394-5880 C_{\gamma}+0.42 T \quad(\mathrm{~J} / \mathrm{mol})
$$

The temperature which satisfies Eq. (38) gives Ms. Martensite volume fraction is a function of temperature below Ms. ${ }^{41)}$

$$
\begin{aligned}
X_{M}= & \left(1-X_{F}-X_{W F}-X_{P}-X_{B}\right) \\
& \cdot\left[1-\exp \left\{-1.10 \times 10^{-2}(\mathrm{Ms}-T)\right\}\right]
\end{aligned}
$$

The nucleation sites and shape of growing grains of each phase are summarized in Fig. 7. These conditions are 


\begin{tabular}{|c|c|c|}
\hline Nucleation sites & \multicolumn{2}{|c|}{ Shape } \\
\hline Polygonal ferrite & \multirow{3}{*}{ within grains } & grain boundary \\
\hline \multirow{2}{*}{$\begin{array}{c}\gamma \text { grain boundary } \\
\text { Annealing twin boundary }\end{array}$} & & \\
\hline & & ellipsoid \\
\hline Widmanstätten ferrite & \multicolumn{2}{|c|}{ within grains grain boundary } \\
\hline \multicolumn{3}{|l|}{$\gamma$ grain boundary } \\
\hline$\gamma / \alpha$ interface & & paraholis \\
\hline Pearlite & \multicolumn{2}{|c|}{ within grains grain boundary } \\
\hline \multicolumn{3}{|l|}{$\gamma$ grain boundary } \\
\hline$\gamma / \alpha$ interface & \multicolumn{2}{|l|}{ spherical } \\
\hline Bainite & within grains & grain boundary \\
\hline \multicolumn{3}{|l|}{$\gamma$ grain boundary } \\
\hline & disc & parabolic \\
\hline
\end{tabular}

Fig. 7. Summary of the nucleation sites and shape of growing grains of each phase.

also assumed for transformation during continuous cooling and that from work-hardened austenite.

\section{Continuous Cooling Transformation Kinetics}

\subsection{General}

A continuous cooling transformation can be considered as the sum of short time isothermal holdings at successive temperatures, as shown schematically in Fig. 8. During cooling, new phase is nucleated and grows at each temperature with the corresponding nucleation and growth rates, e.g. at temperature $T_{i}$ grains of new phase are nucleated at the rate $I_{s}\left(T_{i}\right)$ and grow at the rate $a\left(T_{i}\right)$, as shown schematically in Fig. 9, where $I_{s}\left(T_{i}\right)$ and $a\left(T_{i}\right)$ are, respectively, the nucleation rate and the growth rate in the isothermal transformation at temperature $T_{i}$.

\subsection{Polygonal Ferrite}

The radius of ferrite grain at temperature $T_{n}$ which is nucleated at temperature $T_{1}$

$$
R^{2}\left(T_{n}, T_{1}\right)=\sum_{i=1}^{n} a^{2}\left(T_{i}\right) t_{i}
$$

The number of ferrite grains nucleates at temperature $T_{k}$ during cooling with cooling rate $Q(T)$

$$
N\left(T_{k}\right)=-\frac{I\left(T_{k}\right)}{Q\left(T_{k}\right)} d T
$$

Letting $t_{n}=-d T / Q\left(T_{n}\right)$, the radius of ferrite grain on austenite grain boundary at temperature $T_{n}$ which nucleated at temperature $T_{k}$

$$
R\left(T_{n}, T_{k}\right)=\left[-\sum_{i=k}^{n}\left\{\frac{9 a^{2}\left(T_{i}\right)}{Q\left(T_{i}\right)}\right\} d T\right]^{1 / 2}
$$

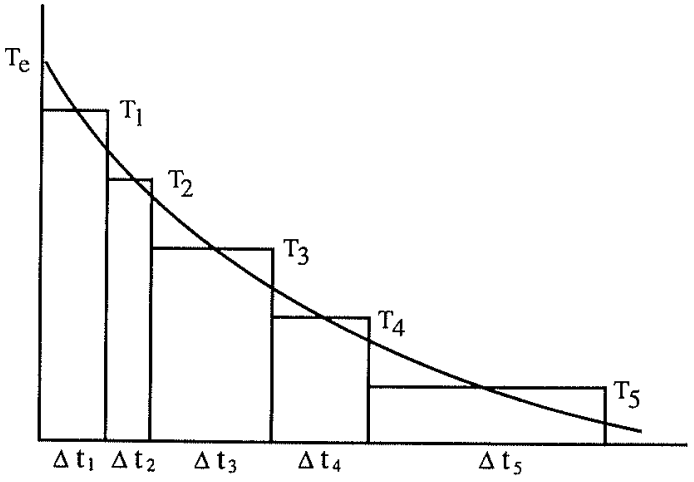

Fig. 8. Diagram showing the approximation of continuous cooling as the sum of short time isothermal holding.

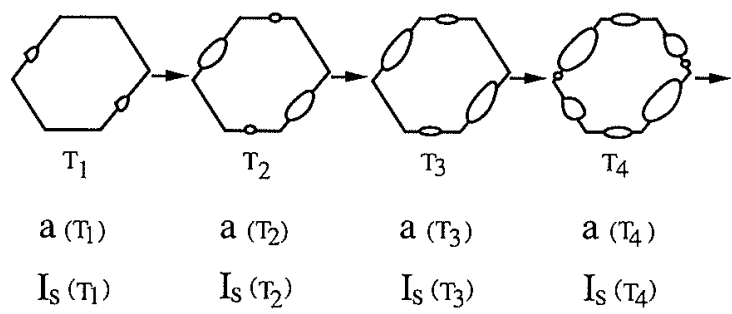

Fig. 9. Schematic illustration showing the formation process of new phase during continuous cooling.

The extended area fraction at temperature $T_{n}$ due to all ferrite grains nucleated between temperature $T_{1}$ and $T_{k}$.

$$
Y_{F}^{e}\left(T_{n}\right)=\sum_{i=1}^{k} N\left(T_{i}\right) \pi\left\{R\left(T_{n}, T_{i}\right)^{2}-y^{2}\right\}
$$

where $k$ satisfies $R\left(T_{n}, T_{k}\right)>y>R\left(T_{n}, T_{k+1}\right)$. The volume occupied by ferrite grains originating from a unit area of austenite grain boundary is then

$$
V_{F}^{S}=2 \int_{0}^{R\left(T_{n}, T_{i}\right)}\left\{1-\exp \left(Y_{F}^{e}\right)\right\} d y
$$

The actual volume fraction of ferrite at temperature $T_{n}$ is given by

$$
F_{F}=1-\exp \left\{-2 S_{\gamma}\left(\frac{C_{\gamma}-C_{\alpha}}{C_{\gamma}-C_{0}}\right) \int_{0}^{R\left(T_{n}, T_{i}\right)} Y_{F} d y\right\} \ldots
$$

\subsection{Pearlite}

The continuous cooling transformation to pearlite can be derived using a similar method. At temperature $T_{n}$ during cooling, the pearlite fraction can be

$X_{p}\left(T_{n}\right)=\left(1-X_{F}-X_{W F}\right)\left\{1-\exp \left(-2 S_{\alpha / \gamma} \int_{0}^{\gamma\left(T_{n}, T_{i}\right)} Y_{p} d y\right)\right\}$

where

$$
Y_{p}=1-\exp \left(Y_{p}^{e}\right)
$$

and

$$
Y_{p}^{e}\left(T_{n}\right)=\sum_{i=1}^{k} N\left(T_{i}\right) \pi\left\{r\left(T_{n}, T_{i}\right)^{2}-y^{2}\right\}
$$

and $k$ satisfies $r\left(T_{n}, T_{k}\right)>y>r\left(T_{n}, T_{k-1}\right)$.

\subsection{Widmanstätten Ferrite and Bainite}

For intragranular nucleation of bainite, the transorma- 
tion kinetics can be derived as follows. The length of bainite lath at temperature $T$ which nucleated at $T_{a}$ during cooling at cooling rate $Q(T)$ is given as

$$
L\left(T, T_{a}\right)=\int_{T}^{T_{a}} \frac{G_{B}(T)}{Q(T)} d T
$$

The extended volume fraction of bainite which nucleated at temperature $T_{a}$ is

$$
\begin{aligned}
{ }^{e} X_{B}^{h}\left(T, T_{a}\right)= & 2\left\{\frac{-I_{h}\left(T_{a}\right)}{Q\left(T_{a}\right)}\right\} d T_{a} \cdot h \cdot \frac{4 \sqrt{2}}{3} \rho_{c}(T)^{1 / 2} \\
& \cdot\left\{\int_{T}^{T_{a}} \frac{G_{B}\left(T^{\prime}\right)}{Q\left(T^{\prime}\right)} d T^{\prime}\right\}^{3 / 2} \ldots \ldots \ldots \ldots \ldots \ldots \ldots \ldots \ldots \ldots \ldots \ldots
\end{aligned}
$$

The extended volume fraction of bainite nucleated from $B_{s}$ to $T$ is

$$
{ }^{e} X_{B}^{h}(T)=\int_{T}^{B_{s}}{ }^{e} X_{B}^{h}\left(T, T_{a}\right) d T_{a}
$$

Thus the volume fraction of bainite at temperature $T$ during cooling for intragranular nucleation is

$$
\begin{aligned}
X_{B}^{h}= & \left(1-X_{F}-X_{W F}-X_{p}\right)\left[1-\exp \left[-\frac{8 \sqrt{2}}{3} h\right.\right. \\
& \left.\left.\cdot \int_{T}^{T_{e}}\left[\frac{\operatorname{Ih}\left(T_{a}\right)}{Q\left(T_{a}\right)} \rho_{c}\left(T_{a}\right)^{1 / 2}\left\{\int_{T}^{T_{e}} \frac{G_{B}\left(T^{\prime}\right)}{Q\left(T^{\prime}\right)} d T^{\prime}\right\}^{3 / 2}\right] d T_{a}\right]\right]
\end{aligned}
$$

For austenite grain boundary nucleation, bainite transformation kinetics is given as

$$
\begin{aligned}
X_{B}^{S}= & \left(1-X_{F}-X_{W F}-X_{p}\right) \\
& \cdot\left[1-\exp \left[-S_{\gamma} \int_{0}^{L\left(T_{n}, T_{i}\right)}\left\{1-\exp \left(-Y_{B}^{e}\right)\right\} d z\right]\right]
\end{aligned}
$$

where

$$
Y_{B}^{e}=\sum_{i=1}^{k}\left[2 \sqrt{2} N\left(T_{i}\right) h \rho_{c}^{1 / 2}\left\{L\left(T_{n}, T_{i}\right)-z\right\}^{1 / 2}\right]
$$

and

$$
L\left(T_{n}, T_{i}\right)=\int_{T_{n}}^{T_{i}} \frac{G_{B}(T)}{Q(T)} d T
$$

\section{Effect of Work-hardening of Austenite on Transfor- mation Kinetics}

\subsection{Polygonal Ferrite}

The increase in the ferrite nucleation rate per unit volume of austenite by work-hardening is attributed (1) to the increase in the austenite grain surface area by elongation of grains, (2) to the increase in the nucleation per sec per unit area of grain surface, and (3) to the formation of additional nucleation site such as annealing twin boundaries, deformation structures, etc.

The surface area of austenite per unit volume of a specimen increases by deformation. The theoretically calculated ratio of the surface area before to after rolling, $q\left(=S_{\gamma} / S_{\gamma}^{0}\right)$, is plotted in Fig. $10^{42)}$ as a function of rolling reduction $p$.

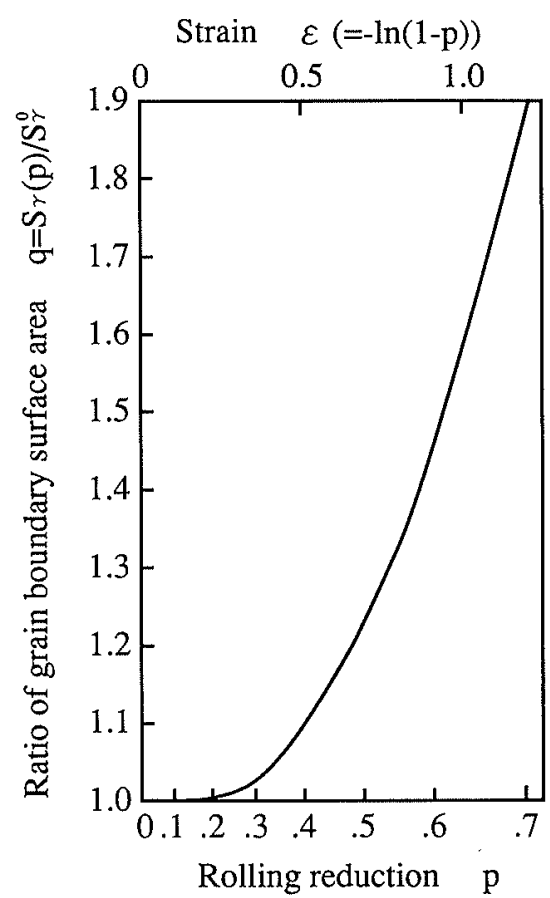

Fig. 10. The ratio of austenite grain boundary surface area before rolling to that of after as a function of rolling reduction $p$. (Ref. 42))

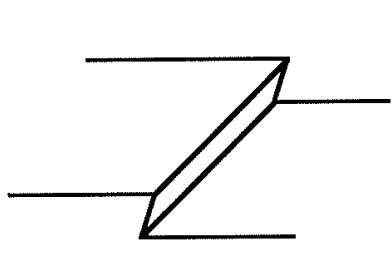

(a)

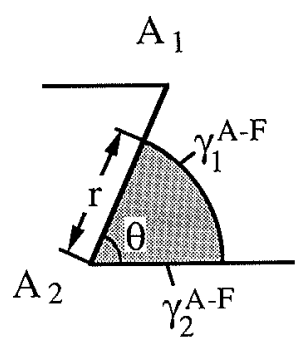

(b)
Fig. 11. Schematic drawing showing ferrite nucleation at a ledge on deformed austenite grain boundaries. (a) a ledge on grain boundary, (b) ferrite nucleation at a ledge. (Ref.43))

The number of ferrite grains nucleated on austenite grain boundaries is substantially increased by the work-hardening of austenite. The mechanism of enhanced nucleation is considered to be as follows. The deformed austenite grain boundaries may exhibit ledges (or steps) shown schematically in Fig. 11. ${ }^{30}$ ) If ferrite nucleates at the corner of such a ledge, as shown in Fig. 11(b), the activation energy for nucleation becomes about $\theta / \pi$ times less than that for nucleation on a planar grain boundary. When more than a certain number of dislocations slip on a given slip plane, the intersection of such slip planes with grain boundary considered to become preferential nucleation site of ferrite. This ledge is called as "effective deformation ledge". The density of effective deformation ledges as a function of strain was theoretically estimated. ${ }^{43)}$

Deformation structures within austenite are characterized by a high density of cells consisting of tangled dislocations. Dislocation favors nucleation through its stress field. When ferrites nucleate on dislocations the free energy change associated with the nucleation of 


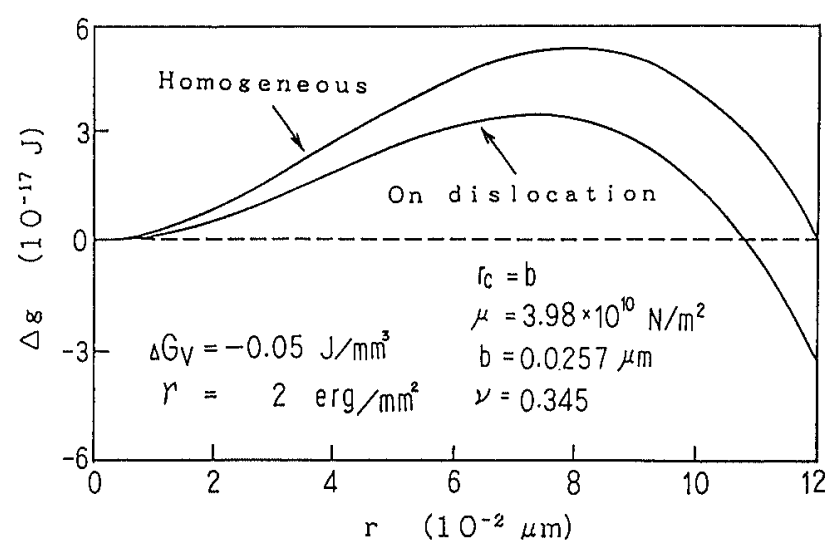

Fig. 12. Variation of $\Delta g$ as a function of nucleus radius $r$ for homogeneous nucleation and that on a dislocation.

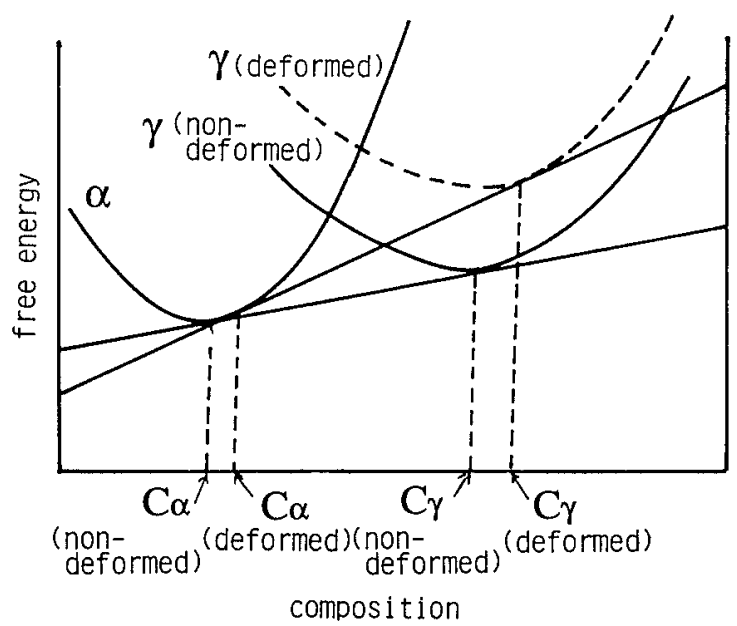

Fig. 13. Free energy $v s$. composition diagram showing schematically the effect of austenite deformation on the equilibrium composition in ferrite and austenite. (Ref. 44))

spherical nucleus with radius $r$ is

$$
\Delta g_{d}=\frac{4}{3} \pi r^{3} \Delta G_{F}-E(r)+4 \pi r^{2} \sigma_{\alpha \gamma}
$$

where $E(r)$ is the elastic energy of dislocation within the spherical region with radius $r$. Figure 12 shows the variation of $\Delta g$ as a function of $r$. The $\Delta g$ maximum $\left(\Delta g^{*}\right)$ for nucleation on dislocation is much smaller than that for homogeneous nucleation.

When ferrite grains grow into deformed austenite, their growth rate would be accelerated with stored energy. The parabolic rate constant of growth of ferrite is given by Eq. (6). Figure $13^{44)}$ schematically shows the effect of work-hardening of austenite on the free energy vs. composition diagram. The free energy of work-hardened austenite is higher than that of non-deformed austenite by a stored energy. It should be noted that the equilibrium compositions of ferrite and austenite in work-hardened specimen, $C_{\alpha}$ (deformed) and $C_{\gamma}$ (deformed), are higher than those in non-deformed specimen.

Figure 14 shows the parabolic rate constant for deformed and non-deformed austenite in an $\mathrm{Fe}-0.1 \mathrm{C}-$ $0.1 \mathrm{Si}-1.0 \mathrm{Mn}-0.2 \mathrm{Cr}-0.2 \mathrm{Ni}$ alloy calculated from $\mathrm{Eq}$. (6) and our thermodynamic program. ${ }^{30)}$ The parabolic rate

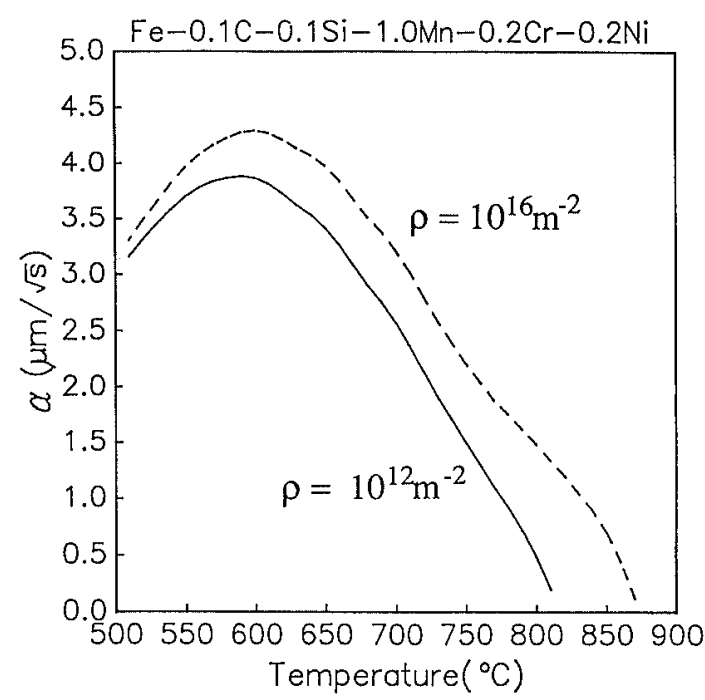

Fig. 14. Calculated parabolic rate constants for deformed $\left(\rho=10^{16} \mathrm{~m}^{-2}\right)$ and non-deformed $\left(\rho=10^{12} \mathrm{~m}^{-2}\right)$ austenite as a function of temperature in an $\mathrm{Fe}$ $0.1 \mathrm{C}-0.1 \mathrm{Si}-1.0 \mathrm{Mn}-0.2 \mathrm{Cr}-0.2 \mathrm{Ni}$ alloy. (Ref. 30 ))

constant in work-hardened austenite is larger than that in non-deformed austenite. The increase in the parabolic rate constant by work-hardening becomes less with the decrease in transformation temperature.

As discussed above, in the work-hardened austenite, ferrite nucleates on $\gamma$ grain boundaries, annealing twin boundaries and dislocations within the $\gamma$ grains. The volume fraction of $\alpha$ can be given by the sum of the three extended volume fractions of the ferrite nucleated on these three types of sites.

$$
X_{t}=1-\exp \left\{-\left(X_{g \cdot b}^{e x}+X_{a \cdot t}^{e x}+X_{i}^{e x}\right)\right\}
$$

\subsection{Pearlite}

Figure $15^{42)}$ shows the progress of isothermal transformation to pearlite in deformed and non-deformed specimen of nearly eutectoid SKD 6 steel. It can be seen that the deformation of austenite clearly accelerated the pearlite transformation. From these pictures it is also noted that in deformed specimen pearlite nucleates at various type sites such as austenite grain boundaries, annealing twin boundaries and deformation structures within grains. It is noted that the effect of workhardening of austenite on the nucleation sites of pearlite is quite similar to that of polygonal ferrite. It was also observed $^{42)}$ that the effect of work-hardening of austenite on the growth rate of pearlite is not significant.

\subsection{Bainite}

Figure $16^{45)}$ shows the bainite transformation curves at $360^{\circ} \mathrm{C}$ in $\mathrm{Fe}-3.6 \mathrm{Ni}-1.45 \mathrm{Cr}-0.5 \mathrm{C}$ alloy. The number on each curve indicates the amount of deformation applied at $600^{\circ} \mathrm{C}$ in austenite condition. It is seen that the deformation of austenite does not change the bainite transformation rate significantly.

The effect of deformation temperature on bainite transformation rate was studied using the same alloy. ${ }^{45)}$ It was found that when deformation temperature is below $500^{\circ} \mathrm{C}$, bainite transformation rate increases with the decrease in deformation temperature. However, when 

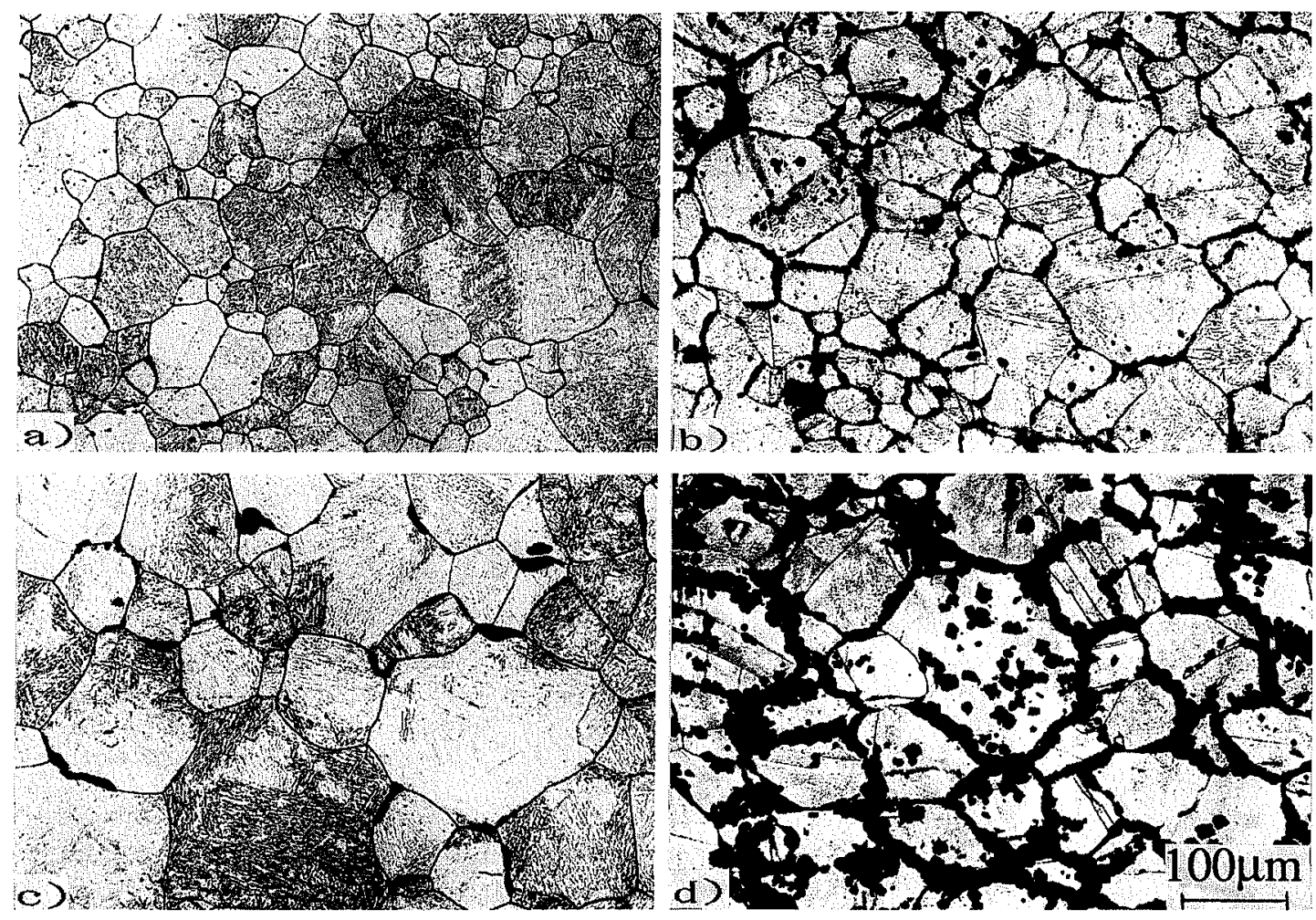

Fig. 15. Optical micrographs showing the progress of transformation to pearlite in deformed and non-deformed specimen of SKD-6 steel. Specimens were deformed at $650^{\circ} \mathrm{C}$ in austenite condition and transformed to pearlite at $715^{\circ} \mathrm{C}$ for 20 or $30 \mathrm{~min}$. (a) non-deformed, $20 \mathrm{~min}$, (b) $30 \%$ rolled, $20 \mathrm{~min}$, (c) non-deformed, $30 \mathrm{~min}$, (d) $30 \%$ rolled, $30 \mathrm{~min}$.

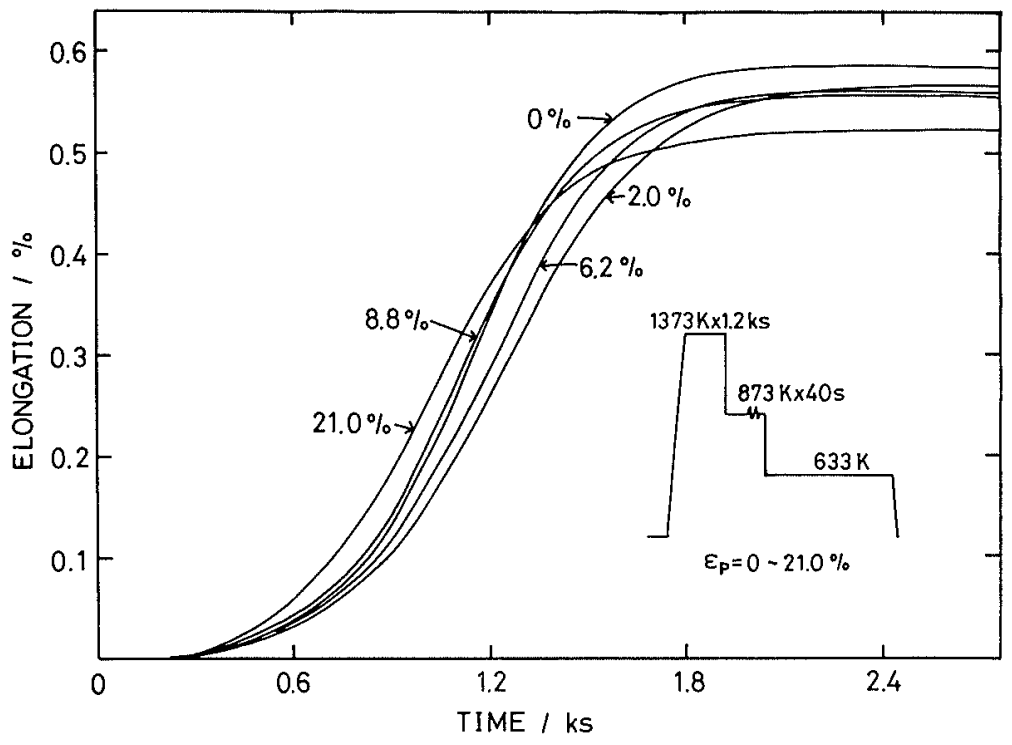

Fig. 16.

The transformation curves of bainite at $360^{\circ} \mathrm{C}$ in $\mathrm{Fe}-3.6 \mathrm{Ni}-1.45 \mathrm{Cr}-0.50 \mathrm{C}$ alloy. Specimens were deformed at $600^{\circ} \mathrm{C}$ in austenite condition ranging from 0 to $21 \%$ as indicated on each curve before the start of transformation. (Ref. 45)) deformation temperature is above $500^{\circ} \mathrm{C}$, the transformation rate does not alter. Thus it can be said that deformation of austenite at temperature above $700^{\circ} \mathrm{C}$ (which is the case in most of the hot-rolling process) does not influence the bainite transformation rate. This is a big difference from that of ferrite and pearlite transformation.

\section{Concluding Remarks}

A computer program which simulates the transformation which occurs during thermo-mechanically controlled process is developed. This program includes the principle of physical metallurgy as much as possible. This paper explained the derivation of basic kinetic equations. For isothermal transformation, the kinetics of austenite transformation to polygonal ferrite, Widmanstätten ferrite, pearlite, bainite and martensite were described. The theoretical estimation of $\alpha / \gamma$ interface area was discussed in detail. For the above transformation products, continuous cooling transformation kinetics were constructed as nucleation and growth process assuming that continuous cooling is the sum of short time isothermal holding at successive temperatures. The 
effect of work-hardening of austenite on transformation kinetics were examined in detail about the nucleation and growth rate of polygonal ferrite. The acceleration mechanism of nucleation rate was discussed and a trial of numerical estimation of nucleation rate was presented. Finally the effect of work-hardening of austenite on the transformation to pearlite and bainite was discussed.

\section{REFERENCES}

1) T. Tanaka: Int. Met. Rev., (1981), 185.

2) J. J. Irani, D. Burton and F. Keyworth: J. Iron Steel Inst., 204 (1966), 702.

3) J. J. Irani and G. Tither: Strong Tough Structure Steel, ISI, London, (1967), 135.

4) T. R. Morgan, E. E. Dancy and M. Korchynsky: J. Met. (1965), 829.

5) M. Korchynsky and H. Stuart: Proc. Int. Conf. Low Alloy High-Strength Steels, Nuremberg, (1970), 17.

6) C. Ouchi, J. Tanaka, I. Kozasu and K. Tsukada: Optimization of Processing, Properties, and Service Performance through Microstructural Control, STP 672, ASTM, (1979), 105.

7) C. M. Sellars and J. A. Whiteman: Controlled Processing of HSLA Steels, Product Technology Conf., York, England, (1976).

8) C. M. Sellars and J. A. Whiteman: Met. Sci., 13 (1979), 187.

9) C. M. Sellars: Hot Working and Forming Processes, ed. by C. M. Sellars and G. J. Davies, Met. Soc., London, (1980), 3.

10) J. S. Kirkaldy: Metall. Trans., 4 (1973), 2327.

11) M. Umemoto, N. Komatsubara and I. Tamura: J. Heat Treat., $1(1980), 57$

12) M. Umemoto, N. Nishioka and I. Tamura: J. Heat Treat., 2 (1981), 130

13) P. K. Agawal and J. K. Brimacombe: Metall. Trans., 12B (1981), 121.

14) Y. Saito, M. Saeki, M. Nishida, Y. Ito, T. Tanaka and S. Takizawa: Proc. of Int. Conf. on Steel Rolling, ISIJ, Tokyo, (1980), 1309

15) K. Esaka, J. Wakita, M. Takahashi, O. Kawano and S. Harada: Seitetsu-Kenkyu, (1986), No. 321, 92.

16) Y. Saito, C. Shiga and T. Enami: THERMEC-88, Vol. 2, ISIJ, Tokyo, (1988), 753.

17) P. J. Campbell, P. D. Hodgson, M. Lee and R. K. Gibbs: THERMEC-88, Vol. 2, ISIJ, Tokyo, (1988), 761.

18) Ch. Perdrix, B. Chamont, E. Amoris and H. Biausser: THERMEC-88, Vol. 2, ISIJ, Tokyo, (1988), 807.

19) M. Suehiro, K. Sato, H. Yada, T. Senuma, H. Shigefuji and $Y$ Yamashita: THERMEC-88, Vol. 2, ISIJ, Tokyo, (1988), 791.
20) A. Yoshie, M. Fujioka, H. Morikawa and $Y$. Onoe: THERMEC-88, Vol. 2, ISIJ, Tokyo, (1988), 799.

21) J. K. Brimacombe, E. B. Hawbolt, I. V. Samarasekera, P. C. Campbell and C. Devadas: THERMEC-88, Vol. 2, ISIJ, Tokyo, (1988), 783

22) P. Choquet, P. Fabregue, J. Giusti, B. Chamont, J. N. Pezant and F. Blanchet: Proc. of Int. Symp. on Mathematical Modelling of Hot Rolling of Steel, CIM, Montréal, (1990), 33.

23) E. Anelli: Proc. of Int. Symp. on Mathematical Modelling of Hot Rolling of Steel, CIM, Montréal, (1990), 44

24) T. Abe, T. Honda, S. Ishizaki, H. Wada, N. Shikanai and T. Okita: Proc. of Int. Symp. on Mathematical Modelling of Hot Rolling of Steel, CIM, Montréal, (1990), 66.

25) M. Suehiro, H. Yada, T. Senuma and K. Sato: Proc. of Int. Symp. on Mathematical Modelling of Hot Rolling of Steel, CIM, Montréal, (1990), 128.

26) M. Umemoto: Proc. of Int. Symp. on Mathematical Modelling of Hot Rolling of Steel, CIM, Montréal, (1990), 404.

27) K. J. Lee, K. B. Kang, J. K. Lee, O. Kwon and R. W. Chang: Proc. of Int. Symp. on Mathematical Modelling of Hot Rolling of Steel, CIM, Montréal, (1990), 435.

28) T. Inoue, S. Nanba, M. Katsumata and G. Anan: Proc. of Int Symp. on Mathematical Modelling of Hot Rolling of Steel, CIM, Montréal, (1990), 290.

29) M. Hillert and L. I. Staffanson: Acta Chem. Scand., 24 (1970), 3618.

30) S. Nanba, M. Kitamura, M. Shimada, M. Katsumata, T. Inoue, H. Imamura, Y. Maeda and S. Hattori: ISIJ. Int., 32 (1992), 377.

31) C. Zener: J. Appl. Phys., 20 (1949), 950.

32) J. W. Cahn: Acta Metall., 4 (1956), 449.

33) J. R. Bradley, J. M. Rigsbee and H. I. Aaronson: Metall. Trans., 8A (1977), 323.

34) K. Russell: Acta Metall., 16 (I969), 1123.

35) M. Hillert: Jernkont. Ann., 141 (1957), 757

36) H. K. D. H. Bhadeshia: Acta Metall., 29 (1981), 1117.

37) H. K. D. H. Bhadeshia: Met. Sci., 16 (1982), 159.

38) W. Steven and A. G. Haynes: J. Iron Steel Inst., 183 (1956), 349.

39) R. Trivedi: Metall. Trans., 1 (1970), 921.

40) T. Y. Hsu and C. Hongbing: Acta Metall., 32 (1984), 343.

41) D.P. Koistinen and R. E. Marburger: Acta Metall., 7 (1959), 59.

42) M. Umemoto, H. Ohtsuka and I. Tamura: Trans. Iron Steel Inst. Jpn., 33 (1983), 775.

43) M. Umemoto, H. Ohtsuka and I. Tamura: THERMEC-88, Vol. 2, ISIJ, Tokyo, (1988), 769.

44) M. Umemoto and I. Tamura: Proc. Int. Conf. on HSLA Steels '85, ASM, (1985), 373.

45) M. Umemoto, S. Bando and I. Tamura: Proc. ICOMAT-86, JIM, Sendai, (1986), 595. 